\title{
Characterization of microcrystalline I-layer for solar cells prepared in low temperature - plastic compatible process
}

\author{
Rafal Sliz $^{a}$, Arman Ahnood ${ }^{b}$, Arokia Nathan $^{b}$, Risto Myllyla ${ }^{a}$ and Ghassan Jabbour ${ }^{a c}$ \\ ${ }^{a}$ Optoelectronics and Measurement Techniques Laboratory, University of Oulu, Erkki \\ Koiso-Kanttilan katu 3, 90570 Oulu, Finland; \\ ${ }^{b}$ Centre for Advanced Photonics and Electronics, Cambridge University, 9 JJ Thomson \\ Avenue, Cambridge CB3 0FA, UK ; \\ ${ }^{c}$ Solar and Alternative Energy Engineering Research Center, KAUST, Thuwal, 23995-6900, \\ Saudi Arabia
}

\begin{abstract}
Microcrystalline silicon (mc-Si) films deposited using a Plasma Enhanced Chemical Vapour Deposition (PECVD) process constitute an important material for manufacturing low-cost, large-area thin-film devices, such as solar cells or thin-film transistors. Although the deposition of electronic-grade mc-Si using the PECVD process is now well established, the high substrate temperature required $\left(\sim 300^{\circ} \mathrm{C}\right)$ does not lend itself to electronic devices with flexible form factors fabricated on low-cost plastic substrates. In this study, we first investigated an intrinsic mc-Si layer deposited at plastic-compatible substrate temperatures $\left(150^{\circ} \mathrm{C}\right)$ by characterising the properties of the film and then evaluated its applicability to p-i-n solar cells though device characterisation. When the performance of the solar cell was correlated with film properties, it was found that, although it compared unfavourably with mc-Si deposited at higher temperatures, it remained a very promising option. Nonetheless, further development is required to increase the overall efficiency of mc-Si flexible solar cells.
\end{abstract}

Keywords: low temperature, solar cells, silicon, flexible, plastic, PEN, PET, PECVD, I-layer, microcrystalline, nanocrystalline

\section{INTRODUCTION}

Prevention of climate change requires the use of carbon-free energy production technologies, such as solar power, wind power and fuel-cell technologies. The energy of solar radiation reaching the earth is many times greater than the current global power consumption, giving solar power a huge potential for future use. Although a large variety of technologies exist for solar energy conversion, photovoltaic solar cells are the most commonly used devices for the direct conversion of sunlight into electrical energy. Low-cost large-area thin-film photovoltaic solar cells (a-Si, Organic and DSSC) have been developed to compliment their high-cost, high-efficiency crystalline silicon (c-Si) counterparts ${ }^{1}$ and are paving the way to low-cost renewable electricity. Furthermore, thin-film inorganic, organic and organic-inorganic hybrid solar cells on flexible substrates using high-throughput (often roll-to-roll printing) fabrication technologies can be integrated into, not installed on, various surfaces allowing the development of such advances as mobile energy harvesting systems or integrated solar cells, with the additional benefits of light weight and low cost.

Microcrystalline silicon (mc-Si) films deposited in a PECVD process constitute a very promising way to manufacture a low-cost, large-area thin-film devices such as solar cells or thin-film transistors. ${ }^{2-4}$ Although the PECVD method is well established and allows fabrication of high quality films, ${ }^{5,6}$ it requires high temperature processing $\left(\sim 300^{\circ} \mathrm{C}\right) .^{7,8}$ Unfortunately, some of the most common lightweight flexible substrates (PET, PEN) are not compatible with temperatures above $200 \mathrm{C}$. Thus, there is a need to develop PECVD deposition methods that produce high quality films at temperatures below $200^{\circ} \mathrm{C}$. Recent research has suggested that growing mc$\mathrm{Si}$ solar cells at plastic-compatible temperatures is a promising option, ${ }^{9,10}$ although further development is

Further author information: (Send correspondence to rafal@ee.oulu.fi)

Photonics for Solar Energy Systems IV, edited by Ralf Wehrspohn, Andreas Gombert,

Proc. of SPIE Vol. 8438, 84381E - (C) 2012 SPIE · CCC code: 0277-786X/12/\$18 · doi: 10.1117/12.922302

Proc. of SPIE Vol. 8438 84381E-1 
necessary to achieve optimum efficiency. Additionally, an accurate electrical and physical characterization of deposited layers is crucial to gain an insight into the physical principles governing the operation of mc-Si solar cells.

In this study, we report processing and characterization results of an intrinsic mc-Si layer made in a plasticsubstrate compatible process. In addition, the developed and evaluated layer was used to manufacture a p-i-n solar cell for currrent-voltage $(\mathrm{J}-\mathrm{V})$ and quantum efficiency characterization.

\section{METHODS}

The investigated intrinsic mc-Si layer was grown in the PECVD $13.56 \mathrm{MHz}$ process and temperature of $150^{\circ} \mathrm{C}$. Prior the deposition of the silicon layer, samples were solvent-cleaned and dried using dry nitrogen. The deposition process was performed at a process pressure of 2 Torr and plasma power of $10 \mathrm{~W}$, using a gas flow ratio of $1 / 100$ for $\left[\mathrm{SiH}_{4}\right] /\left[\mathrm{H}_{2}\right]$. These parameters were defined on the basis of a literature review and previous experiments. ${ }^{11}$

Film thickness was measured using a Dektak 8 profilometer. To extract the conductivity of i-layer a dark, and photo current-voltage measurements were performed. A chromium-gap cells evaporated using shadow masks at a base pressure of $8.6^{-7}$ Torr on a Corning Eagle 2000 glass substrate were measured using a Keithley 4200-SCS semiconductor analysing system. Structural properties and crystal volume fraction were investigated using a Raman spectroscopy system. Raman spectroscopy was performed using a Horiba Jobin-Yvon Labram HR800 UV-VISRAMAN on the glass substrate with a green laser light to ensure a penetration depth comparable to the sample thickness. X-Ray Diffraction (XRD) measurements were performed using a wavelength of $0,711 \AA$ at the power of $40 \mathrm{kV} 50 \mathrm{~mA}$ on mc-Si deposited on the glass substrate. Atomic Force Microscopy (AFM) was performed on the c-Si substrate using an $10 \mathrm{~nm}$ tip with the Veeco D3100 system. ${ }^{12}$ The Fourier Transform Infrared Spectroscopy (FTIR) spectrum was measured using the Perkin Elmer System ONE on samples deposited on lightly doped p-type c-Si substrates. Additionally, a reference spectrum was obtained by measuring a bare substrate from the same batch treated in an identical way. Visualization of deposited microcrystalline layer and determination of the seed layer thickness were performed by Transmission Electron Microscopy (TEM) measurements using a LEO 912 OMEGA EFTEM.

Finally, based on results, the most promising i-layer was used for fabrication and measurement of solar cells with a p-i-n structure and area $4 \mathrm{~mm}^{2}$. The final structure was tested to extract its external and internal quantum efficiency, measured with an Automated Spectroradiometric Measurement System - OPTRONIC LABORATORIES. Additionally, the Oriel Sol3A Class AAA AM1.5G solar simulator calibrated with a NREL certified silicon solar cell, was used for J-V measurements that resulted with Isc, Voc, FF and Rs parameters of the tested solar cell.

\section{RESULTS}

The deposition rate of mc-Si achieved in this work was $0.5 \AA / \mathrm{s}$, which is relatively slow, compared to that of high-temperature mc-Si. This parallels the slower growth rate of device-grade low-temperature a-Si:H relative to high-temperature a-Si:H. In current research, the dark and illuminated photoconductivity of the mc-Si film was $8,37^{-7} \Omega^{-1} \mathrm{~cm}^{-1}$ and $2,23^{-5} \Omega^{-1} \mathrm{~cm}^{-1}$, respectively.

Raman spectroscopy provides a quantitative tool for measuring crystal volume fractions, based on Equation (1), as well as a qualitative tool for determining crystal size and stress in a sample.

$$
X_{C}=\frac{I_{C}+I_{G B}}{I_{C}+I_{G B}+\alpha \cdot I_{A}}
$$

where $I_{A}$ is the amorphous part of the signal, defined as the area under the $480 \mathrm{~cm}^{-1}$ peak, $I_{C}$ is the crystalline component, defined as the area under the sharp peak at $520 \mathrm{~cm}^{-1}, I_{G B}$ is the grain boundary signal attributed to the peak at $510 \mathrm{~cm}^{-1}, \alpha$ is the ratio of phonon scattering cross-sections of crystalline silicon to amorphous silicon. This ratio was assumed to be 0.8. Raman spectra collected in Raman measurements is dependent on the depth of each phase. Thus, the relative proportion of peaks attributed to the a-Si and mc-Si phases on the 


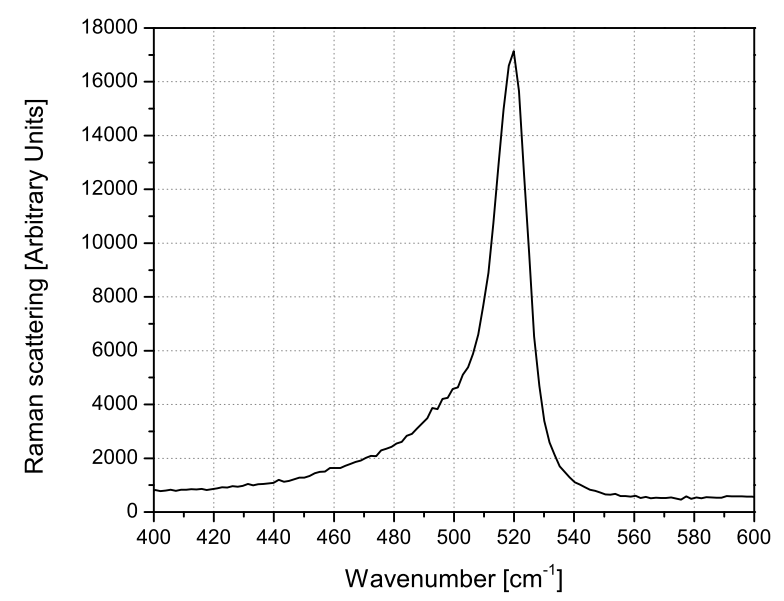

(a) Raman spectra of $150 \mathrm{~nm}$ thick mc-Si i-layer

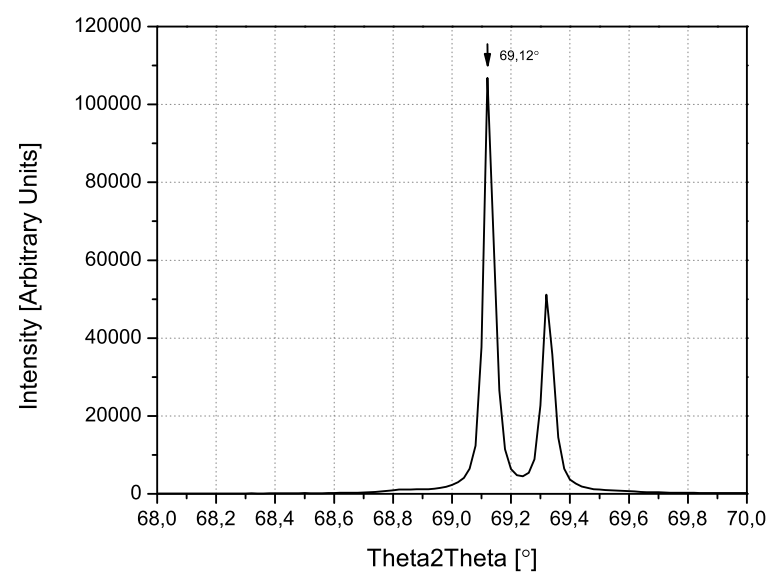

(b) XRD crystallographic analysis of deposited i-layer

Figure 1. Identification of the crystalline phases with X-ray diffraction and Raman spectroscopy analyses

Raman spectra of the silicon thin-film sample can be used as an indication of the crystal volume fraction of the deposited film. Based on this, we may extract a crystal volume fraction of $76,8 \pm 0,5 \%$.

Moreover, mc-Si grain size was extracted from the XRD using the Scherrer Equation ${ }^{13}$ (2):

$$
\tau=\frac{K \cdot \lambda}{\beta \cdot \cos \theta}
$$

where $\tau$ is the size of microcrystals, $\mathrm{K}$ is the shape factor, $\lambda$ is the $\mathrm{x}$-ray wavelength, $\beta$ is the line broadening at half the maximum intensity (FWHM) in radians, and $\theta$ is the Bragg angle, from which the grain size of 24.5 $\mathrm{nm}$ was extracted. This was further verified by examining the surface topography obtained from AFM - Fig. 2, which shows a fairly uniform mc-Si film with features measuring about $30 \mathrm{~nm}$.

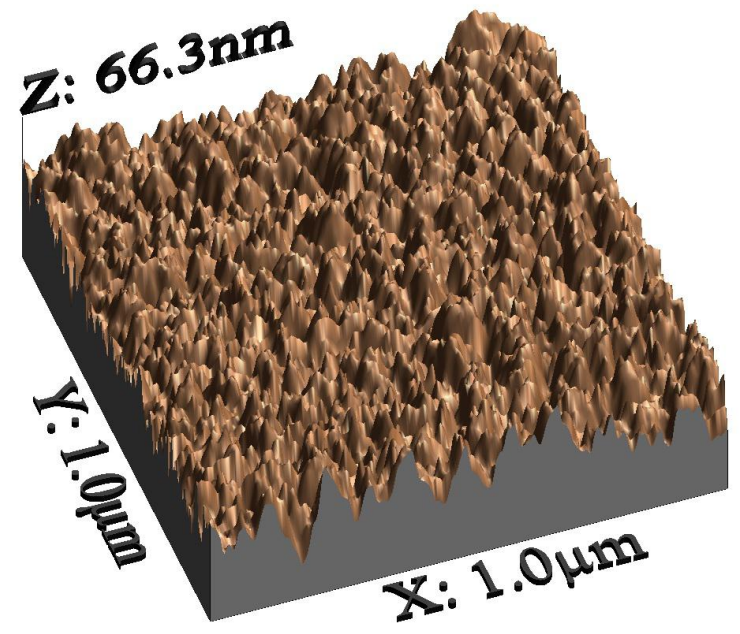

Figure 2. Atomic force microgaphs of mc-Si film

A FTIR analysis was performed on the deposited samples to detect $\mathrm{Si}-\mathrm{H}$ bonds and their relative intensities. Fig. 3 shows the FTIR spectrum of the mc-Si thin film. Seen at 1000 1200 $\mathrm{cm}^{-1},{ }^{14}$ the strong peak associated 
with the stretching vibration mode of Si-O points to the presence of silicon oxide, due to post-deposition oxidation of the thin-film, mediated though the vacuum and dislocations at grain boundaries. ${ }^{15}$

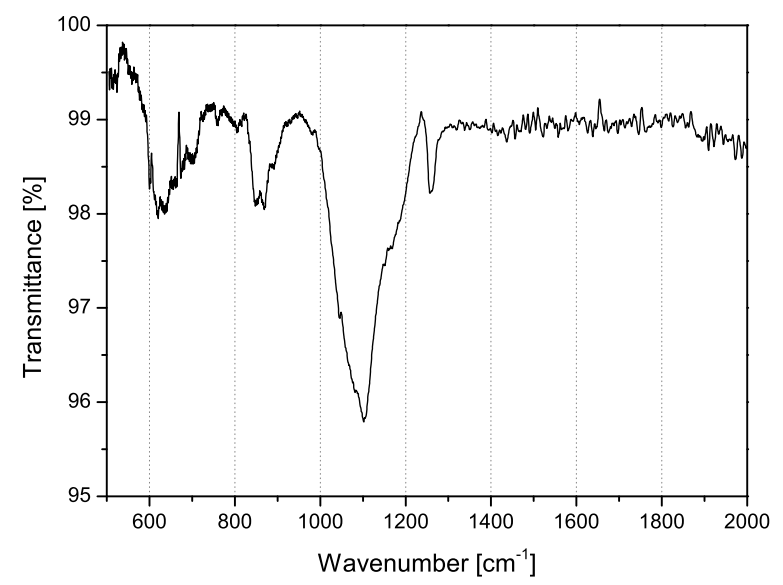

Figure 3. FTIR spectra of mc-Si deposited on doped c-Si

Fig. 4 presents TEM and Scanning Transmission Electron Microscopy (STEM) images, where a clear contrast can be observed between the amorphous-like incubation layer and the micro-crystalline layer, when the thickness of the former is approximately $10 \mathrm{~nm}$.

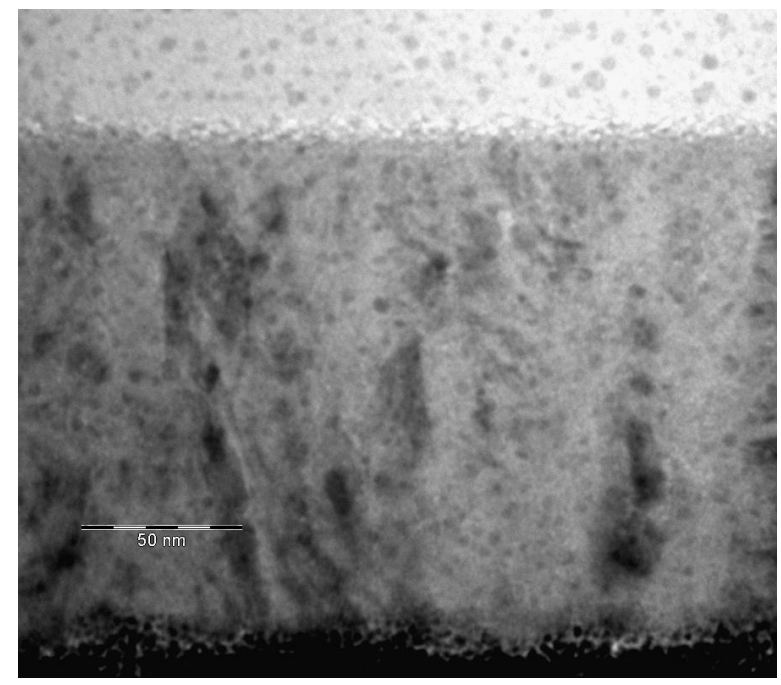

(a) TEM

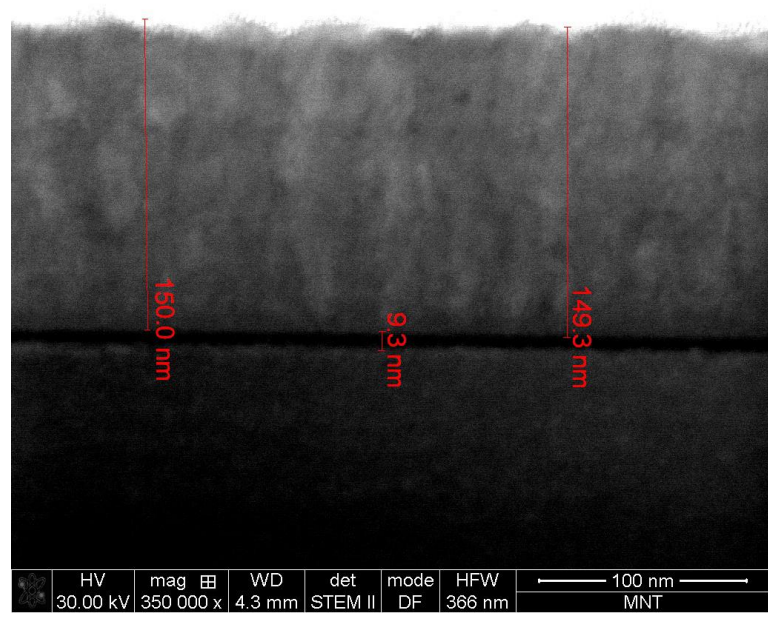

(b) STEM

Figure 4. Microscopic micrographs of I-layer deposited on glass substrate

Photo and dark J-V characteristics and quantum efficiency of the p-i-n solar cell are depicted in Fig. 5(a) and Fig. 5(b), respectively. As the quantum efficiency results indicate, a significant difference between the external and internal quantum efficiency of the measured cell can be observed, suggesting that external quantum efficiency is mostly caused by optical losses during transmission and reflections. Table 1 summarises the key performance parameters of the fabricated solar cell. A dark J-V measurement was used to extract the the solar cells series resistance. 
Table 1. Electrical properties of fabricated solar cell

\begin{tabular}{|c|c|c|c|c|}
\hline Voc $[\mathrm{V}]$ & $\mathrm{Jsc}\left[\mathrm{mA} / \mathrm{cm}^{2}\right]$ & $\mathrm{FF}[\%]$ & $\mathrm{Rs}\left[\Omega-\mathrm{cm}^{2}\right]$ & PCE $[\%]$ \\
\hline $\mathbf{0 , 4 0 9}$ & $\mathbf{3 , 0 1 8}$ & $\mathbf{4 2 , 6}$ & $\mathbf{1 1 , 3 0}$ & $\mathbf{0 , 5 2 7}$ \\
\hline
\end{tabular}

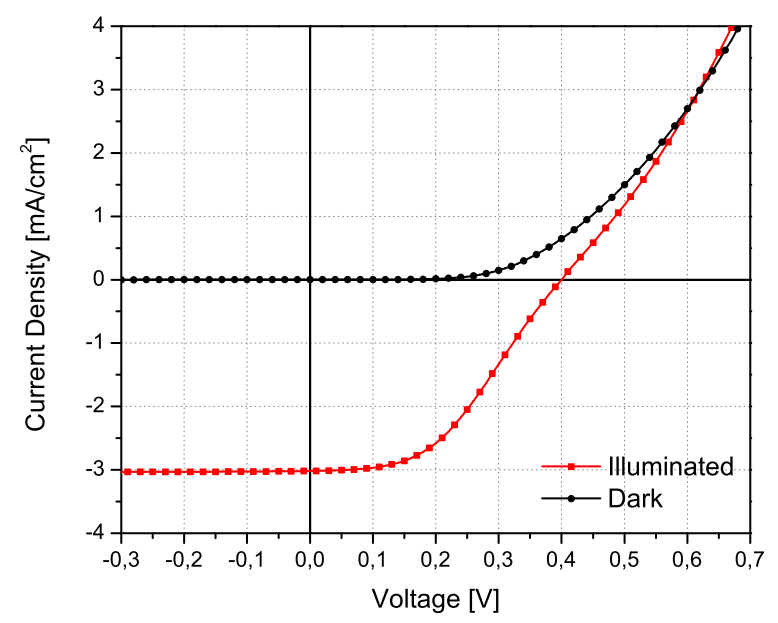

(a) J-V characteristics for fabricated solar cell

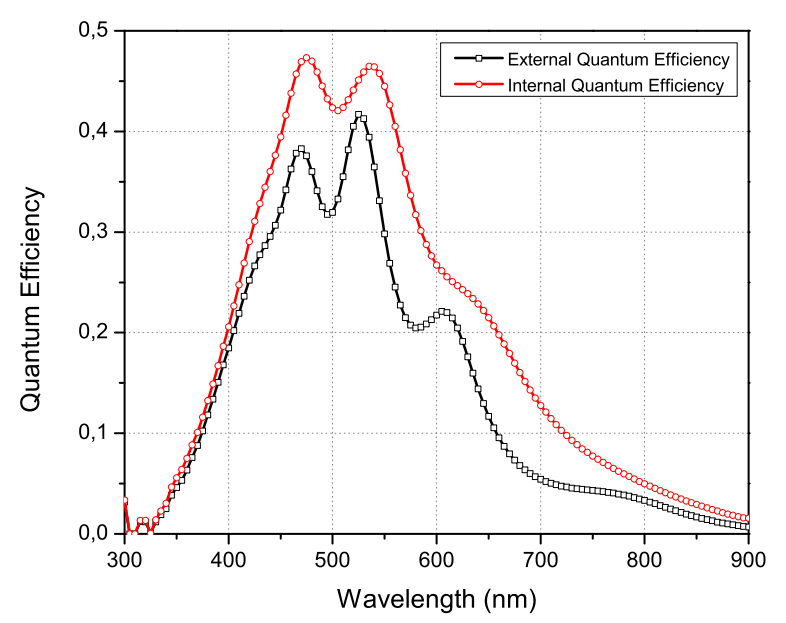

(b) External and Internal Quantum Efficiency of fabricated solar cell

Figure 5. Solar cell characterization plots

\section{DISCUSSION}

Characterization of the deposited intrinsic layer indicates poor electrical properties compared to films deposited at higher temperatures. State of the art single-junction microcrystalline solar cells fabricated in temperatures above $400^{\circ} \mathrm{C}$ achieve power conversion efficiencies of $10 \%,{ }^{16}$ while the solar cell fabricated in this work has an efficiency of $0.5 \%$. Nevertheless, electrical and physical characterizations highlight the weak points responsible for its low power-conversion efficiency. Extracted from Raman spectroscopy, the crystal volume fraction suggests a microstructure resembling that of the state-of-the-art mc-Si. However, the achieved volume fraction is an underestimate, due to the effect of a $10 \mathrm{~nm}$ a-Si:H incubation layer on the $150 \mathrm{~nm}$ thick mc-Si:H layer. This combined with the mc-Si:H film evolution with thickness, the mc-Si:H film grown in this work is expected to have a higher crystallinity. As for grain size, the grain size of $\sim 30 \mathrm{~nm}$, extracted from AFM and XRD, and validated by TEM/STEM, is within the desirable range and consistent with the state-of-the-art mc-Si:H. FTIR suggests a high Si-O bonding content in the mc-Si:H film, which may be caused by voids, as shown in the TEM image. Oxygen in mc-Si has been attributed to p-type deep defects, ${ }^{17}$ leading to a reduction in solar cell efficiency via increased recombination loss and photo-response at the infrared range. ${ }^{18}$ The low short-circuit current density of the solar cell can partly be attributed to optical losses caused by the thin mc-Si:H i-layer (150 $\mathrm{nm}$ ) used in this work. This is because a low photon-absorption coefficient (compared to CIGS, organic or a$\mathrm{Si}: \mathrm{H})$ leads to incomplete light absorption and, therefore, a low rate of photocarrier generation. Although greater in thickness (in the range of few um), mc-Si:H suffers from high mechanical stress, caused by low deposition temperature, which leads to a delamination of the film from the substrate. In addition to the low Isc value, the solar cell exhibits a relatively low FF, which can be partially attributed to high series resistance, as well as to recombination of photocarriers due to defects within the i-layer. Also the Voc value of the cell was rather low, affected mostly by the high crystallinity ratio, which is the limiting factor. ${ }^{19}$ Compared to the state-of-the-art cell, the fabricated solar cell exhibits a very low spectral response in the red spectrum. This is caused by a high defect density at grain boundaries, corresponding to the porous structure and thickness of the i-layer. Spectral response and, therefore, short-circuit current, can be improved significantly by using an optimized back reflector and by increasing the i-layers thickness. As a conclusion, the results highlight the feasibility of low-temperature mc-Si:H solar cell fabrication using PECVD. However, further development is needed to increase the overall efficiency of mc-Si flexible solar cells. 


\section{REFERENCES}

[1] Green, M., "Crystalline and thin-film silicon solar cells: state of the art and future potential," Solar Energy $\mathbf{7 4}(3), 181-192$ (2003).

[2] Shah, A., Torres, P., Tscharner, R., Wyrsch, N., and Keppner, H., "Photovoltaic technology: The case for thin-film solar cells," Science 285(5428), 692-698 (1999).

[3] Vetterl, O., Finger, F., Carius, R., Hapke, P., Houben, L., Kluth, O., Lambertz, A., Mck, A., Rech, B., and Wagner, H., "Intrinsic microcrystalline silicon: A new material for photovoltaics," Solar Energy Materials and Solar Cells 62(12), 97 - 108 (2000).

[4] Schropp, R. E. and Zeman, M., [Amorphous and microcrystalline silicon solar cells: Modeling Materials and Device Technology], Springer (1998).

[5] Gope, J., Kumar, S., Parashar, A., Dixit, P., Rauthan, C., Panwar, O., Patel, D., and Agarwal, S., "Amorphous and nanocrystalline silicon made by varying deposition pressure in pecvd process," Journal of NonCrystalline Solids 355(4547), 2228 - 2232 (2009).

[6] Baghdad, R., Benlakehal, D., Portier, X., Zellama, K., Charvet, S., Sib, J., Clin, M., and Chahed, L., "Deposition of nanocryctalline silicon thin films: Effect of total pressure and substrate temperature," Thin Solid Films 516(12), 3965 - 3970 (2008).

[7] Rath, J., "Nanocystalline silicon solar cells," Applied Physics A: Materials Science 83 Processing 96, 145-152 (2009).

[8] Kondo, M., Matsui, T., Nasuno, Y., Sonobe, H., and Shimizu, S., "Key issues for fabrication of high quality amorphous and microcrystalline silicon solar cells," Thin Solid Films 501(12), 243 - 246 (2006).

[9] Rath, J., Brinza, M., Liu, Y., Borreman, A., and Schropp, R., "Fabrication of thin film silicon solar cells on plastic substrate by very high frequency pecvd," Solar Energy Materials and Solar Cells 94(9), 1534 1541 (2010).

[10] Brinza, M., Rath, J. K., and Schropp, R. E. I., "Thin film silicon deposited at 100 C by VHF PECVD: optoelectronic properties and incorporation in solar cells," physica status solidi (c) 7(3-4), 1093-1096 (2010).

[11] Shah, A., Meier, J., Vallat-Sauvain, E., Wyrsch, N., Kroll, U., Droz, C., and Graf, U., "Material and solar cell research in microcrystalline silicon," Solar Energy Materials and Solar Cells 78(14), 469 - 491 (2003).

[12] Horcas, I., Fernandez, R., Gomez-Rodriguez, J. M., Colchero, J., Gomez-Herrero, J., and Baro, A. M., "WSXM: A software for scanning probe microscopy and a tool for nanotechnology," Review of Scientific Instruments 78(1), 013705 (2007).

[13] Patterson, A. L., "The scherrer formula for x-ray particle size determination," Phys. Rev. 56, 978-982 (Nov 1939).

[14] Lucovsky, G., Nemanich, R. J., and Knights, J. C., "Structural interpretation of the vibrational spectra of a-si: H alloys," Phys. Rev. B 19, 2064-2073 (Feb 1979).

[15] Hugger, P. G., Cohen, J. D., Yan, B., Yue, G., Yang, J., and Guha, S., "Relationship of deep defects to oxygen and hydrogen content in nanocrystalline silicon photovoltaic materials," Applied Physics Letters 97(25), 252103 (2010).

[16] Green, M. A., Emery, K., Hishikawa, Y., Warta, W., and Dunlop, E. D., "Solar cell efficiency tables," Progress in Photovoltaics: Research and Applications 20, 12-20 (2012).

[17] Finger, F., Carius, R., Dylla, T., Klein, S., Okur, S., and Gunes, M., "Stability of microcrystalline silicon for thin film solar cell applications," Circuits, Devices and Systems, IEEE Proceedings - 150, 300-8 (Aug. 2003).

[18] Matsui, T., Matsuda, A., and Kondo, M., "High-rate microcrystalline silicon deposition for p-i-n junction solar cells," Solar Energy Materials and Solar Cells 90(18-19), 3199 - 3204 (2006).

[19] Droz, C., Vallat-Sauvain, E., Bailat, J., Feitknecht, L., Meier, J., and Shah, A., "Relationship between raman crystallinity and open-circuit voltage in microcrystalline silicon solar cells," Solar Energy Materials and Solar Cell 81, 61-71 (2004). 